\title{
Acomodo de la diversidad, reconocimiento y justicia social
}

\section{Accommodating diversity, recognition and social justice}

\author{
MARTA GIL BLASCO \\ UNIVERSITAT DE VALÈNCIA
}

Artículo recibido: 14 enero 2016

Solicitud de revisión: 21 enero 2016

Artículo aceptado: 18 julio 2016

Resumen

En primer lugar, expondremos el trasfondo común que comparten las propuestas multiculturalistas y las intercultralistas, esto es, el particular énfasis que ponen en la necesidad de reconocimiento para la conformación de la personalidad y en las patologías que se derivan de la falta de reconocimiento. En segundo lugar, veremos algunos de los problemas que suscitan los planteamientos multiculturalistas: minorías dentro de las minorías, esencialismo y ausencia de cohesión social. En este punto también expondremos algunas de las propuestas del interculturalismo para superar estos obstáculos. Por último, propondremos la noción de patriotismo constitucional como fórmula para la cohesión social, puesto que éste, al requerir una adhesión de tipo cívico, puede ser abrazado desde cualquier forma de vida particular, además de contemplar el importante papel de la sociedad civil a la hora de dar forma a sus principios a través del Derecho.

Palabras clave: acomodo de la diversidad, justicia social, reconocimiento, multiculturalismo, patriotismo constitucional.

\begin{abstract}
In the first place, we will deal with the common background that multiculturalism and interclturalism share: the emphasis that they put in the necesity of recognition in the conformation of the personality and in the pathologies derived from the absence of recognition. In the second place, we will explore some of the problems that multiculturalism entails: minorities within minorities, essentialism and lack of social cohesion. At this point, we will explain some of the solutions that interculturalism has proposed for these problems. To conclude, we will propose the notion of constitutional patriotism as a means for achieving social cohesion. Constitutional patriotism demands some sort of civic engagement, so it can be supported from every particular cultural form of life. Besides, this proposal takes into account the important role of civic society when it comes to shape its principles through Law.
\end{abstract}

Keywords: acommodation of diversity, social justice, recognition, multiculturalism, constitutional patriotism. 


\section{INTRODUCCIÓN}

Hace ya veinte años que Nancy Fraser (1996) señaló que un nuevo paradigma de justicia social estaba ganando importancia respecto al paradigma tradicional de justicia, basado en la redistribución: el paradigma del reconocimiento. No obstante, Fraser observa con perspicacia que la contraposición entre un modelo de justicia y el otro es falaz, puesto que toda sociedad que se pretenda justa no puede obviar ninguna de las dos dimensiones. El reconocimiento, por tanto, es un aspecto ineludible de la justicia. Tanto los exponentes del multiculturalismo como los del interculturalismo han incidido en la importancia del reconocimiento para la forja de nuestra identidad y nuestro carácter. Por esta razón, dedicaremos gran parte del presente trabajo a ver en detalle las características de este trasfondo común.

Ahora bien, como veremos, multicuralismo e interculturalismo difieren en algunos aspectos, puesto que hay quien considera que la segunda corriente teórica ha superado los escollos con los que ha topado la primera. No obstante, es preciso ser cautelosos, ya que un exceso de énfasis en la dimensión del reconocimiento puede incurrir en diversas formas de injusticia. En el presente trabajo veremos tres derivas perniciosas que se achacan al multiculturalismo y que pueden desembocar en injusticias contra los individuos y en otros problemas de convivencia. Veremos, además, algunas de las propuestas sugeridas desde el interculturalismo para superar estos problemas. Con todo, es preciso advertir que en la literatura sobre el tema también hay quien sostiene que el interculturalismo no aporta ninguna novedad al multiculturalismo, sino que aquél simplemente subraya algunos de los aspectos que ya están contenidos en este planteamiento teórico. ${ }^{1}$ No obstante, para los propósitos del presente trabajo, que consisten en explorar los vínculos entre justicia social y acomodo de la diversidad, esta distinción resulta útil, aunque sólo sea para indagar en qué aspectos el multiculturalismo puede llegar a propiciar situaciones injustas a las que es preciso proponer soluciones.

Ahora bien, partiendo del hecho de que las sociedades y los países son heterogéneos en lo que se refiere a religiones, culturas, hábitos de vida, lenguas, etc., será preciso recurrir a algún elemento que tenga la capacidad de cohesionar toda esta diversidad. Por esta razón, propondremos la no-

1 Se puede encontrar una discusión sobre esta cuestión en Meer y Modood (2012), Wieviorka (2012) y Taylor (2012). 
ción de patriotismo constitucional como mecanismo para articular la diversidad con la necesaria cohesión social.

\section{LA CUESTIÓN DE LA INCLUSIÓN Y EL ACOMODO DE LA DIVERSIDAD}

Comenzaré la exposición haciendo referencia a uno de los tópicos más extendidos de nuestro tiempo. La globalización se caracteriza por la ampliación de las interconexiones que están sufriendo las sociedades contemporáneas. Estos cambios se estarían dando en todos los aspectos de la vida, incluyendo los aspectos culturales, financieros, la comunicación, la criminalidad o el medio ambiente. Una de las consecuencias más evidentes de estos procesos es que las poblaciones cada vez se desplazan más: algunos migran con la esperanza de alcanzar mayores cotas de prosperidad y bienestar; otros huyen de sus países de origen por causas relacionadas con la violencia y la guerra. En este contexto, los gobiernos, y los propios ciudadanos, se ven abocados a gestionar los cambios que estos fenómenos provocan.

También los teóricos políticos tratan de dilucidar las cuestiones relacionadas con la globalización, y de proponer modelos de gestión para la diversidad social que ésta impulsa, tanto en el plano de las ideas políticas como en el de las políticas públicas. El asunto tiene tal alcance, por cierto, que hay quien habla ya de «super diversidad» $\mathrm{O}$ «hiper diversidad» (Cantle, 2012: 4).

Las propuestas para dar acomodo a esta diversidad contemplan numerosas opciones, que van desde las más intolerantes a las más inclusivas. ${ }^{2}$ En uno de los extremos del espectro, encontraríamos la expulsión, que no entraña el mínimo esfuerzo por parte de la sociedad receptora, amén de exacerbar aversiones entre las partes. En segundo lugar, tendríamos la asimilación, que permite al extranjero o miembro de un colectivo minoritario quedarse en un lugar o formar parte de una sociedad, con la condición de que acepte y se amolde la cultura dominante. Aquellos que no se adecuen a los criterios, valores, normas o prácticas de la cultura dominante quedarían marginados. Esta forma de exclusión sería propia del tercer modelo: la segregación. Multiculturalismo $e$ interculturalismo, en el extremo opuesto, serían formas tolerantes e inclusivas de dar respuesta a la diversidad.

2 Esta clasificación es una elaboración propia a partir de Elósegui (1997), Cortina (2009) y Torrens (2006). 
A pesar del «ismo», el multiculturalismo no es en sí mismo una ideología. Más bien, se trata de una corriente de filosofía política o teoría política que explora las diversas formas en que las sociedades pueden acomodar la diversidad cultural. Charles Taylor, Will Kimlicka, Bikhu Parekh o Tariq Modood serían tan sólo algunos ejemplos de autores que se han dedicado a pensar estos problemas. Pese a lo variado de sus ideas, podríamos decir que el multiculturalismo lidia, a grandes rasgos, con las siguientes cuestiones en materia de políticas públicas:

- Lenguas oficiales y su uso en el espacio público.

- Materiales públicos que tienen por finalidad proporcionar información a la población sobre cuestiones de interés público -por ejemplo, en materia de sanidad, derecho a voto, escolarización, etc.

- Reconocimiento público por parte de las instituciones para minorías étnicas u otros colectivos tradicionalmente desaventajados.

- Elaboración de directrices sensibles a las cuestiones relacionadas con las minorías culturales en servicios públicos, tales como la sanidad, los juzgados o los cuerpos de seguridad.

- Permisos especiales relacionados con los horarios de culto, los rituales -funerarios, de transición a la vida adulta, etc.-, y el establecimiento de lugares de culto.

- Elaboración de currículos educativos que tengan en cuenta la cultura o valores de colectivos minoritarios.

- Excepciones de tipo legal -por ejemplo, no hacer jurar sobre una Biblia a un miembro de otra religión.

- Excepciones en lugares públicos relativos a la alimentación, los códigos de vestimenta y otros usos y costumbres.

- Imagen pública de los grupos minoritarios.

- Elección de días festivos públicos.

- Otras cuestiones relacionadas con la cohesión social y la ciudadanía compartida.

El multiculturalismo, no obstante, no tiene que ver únicamente con las políticas públicas, sino que tiene también una dimensión individual e íntima, por cuanto el tratamiento público que reciben las adscripciones culturales de una persona pueden afectar directamente a su autoestima y a la imagen que tiene de sí misma. Por decirlo con rawlsiana expresión: el autorespeto tiene unas bases sociales, y además constituye uno de los más importantes bienes primarios. Este sentido de la propia dignidad -pode- 
mos añadir- viene condicionado por el respeto con el que son tratados determinados atributos de carácter cultural.

El interculturalismo, por su parte, se presentaría como una suerte de «post-multiculturalismo» (Kymlicka, 2010) o superación del multiculturalismo con capacidad para plantear una «convivencia en la diversidad», aceptando que «detrás de la diversidad cultural hay unos valores comunes» (Elósegui, 1997: 25), y que las propias particularidades se pueden traspasar en aras de la convivencia y la búsqueda de estos valores con cierto grado de universalidad.

\section{EL TRASFONDO COMÚN DEL MULTICULTURALISMO Y EL INTERCULTURALISMO: LA ÉTICA Y LA POLÍTICA DEL RECONOCIMIENTO}

El multiculturalismo se encuentra estrechamente vinculado con la «ética del reconocimiento» (Taylor, 1994; Honneth, 1997), y con las denominadas «políticas del reconocimiento», las "políticas de la diferencia» y las «políticas de la identidad» (Young, 1990; Taylor, 1994; Gutmann, 2003), variantes de una corriente de pensamiento que subraya la importancia de los otros en la construcción de nuestro yo o nuestra identidad. Por otra parte, dado que el interculturalismo es una versión modificada del multiculturalismo, hunde sus raíces en el mismo sustrato filosófico.

No podemos proseguir la exposición sin hacer una breve mención a Hegel, cuyo legado se encuentra presente en la corriente de pensamiento referida. De acuerdo con Honneth, uno de los más destacados intérpretes de Hegel, éste se basó, a su vez, en Fichte para reconstruir el desarrollo de la moralidad humana. Fichte estaría convencido de que los sujetos sólo pueden adquirir conciencia de su libertad desafiando a otros a ejercer su autonomía y reconociendo a los otros -y también siendo reconocidos por ellos-, como personas libres. Hegel recompondría esta idea para sostener que «la autoconciencia humana depende de la experiencia interpersonal de ser reconocido por otros seres humanos» (Honneth, 1998). Para Hegel, además, la experiencia del reconocimiento sería una suerte de motor en el desarrollo de la moralidad, puesto que el progreso moral tiene lugar en diferentes estadios de reconocimiento. Estos estadios se alcanzarían mediante una lucha interpersonal en la que los sujetos se involucrarían para reivindicar su identidad. La identidad, en definitiva, se fraguaría en nuestra relación con los otros, en forma de lucha. 
El breve ensayo de Charles Taylor The Politics of Recognition es uno de los textos fundacionales del multiculturalismo. En él, Taylor defiende que hay un vínculo entre reconocimiento e identidad, entendiendo esta última como la idea que las personas tienen de sí mismas, de quienes son y de las características que les definen como seres humanos. Así pues,

La tesis es que nuestra identidad está parcialmente conformada por el reconocimiento o su ausencia [...], por lo que una persona o un grupo de personas pueden sufrir un daño real, una distorsión real, si la gente o la sociedad que tiene a su alrededor les devuelve una imagen limitada, degradada o despreciable de sí mismos. El mal reconocimiento o la falta de reconocimiento pueden infligir un daño, puede ser una forma de opresión, encarcelando a alguien en un modo de ser falso, distorsionado y reducido (25).

De este modo, nuestra identidad individual no es, o por lo menos no es solamente, una creación propia. Sólo a través de la interacción con los otros, particularmente con aquellos que Taylor denomina «otros significativos»-es decir, aquellas personas a quien otorgamos cierta relevancia en nuestras vidas, como los familiares, los amigos o los compañeros de trabajo-, vamos ajustando y forjando nuestra identidad. ${ }^{3}$

En una línea similar, criticando algunas de las ideas más características de la modernidad, Taylor desaprueba la idea de libertad como autodeterminación, entendida como la capacidad de decidir por uno mismo prescindiendo de toda influencia externa. Esta idea de libertad, arguye Taylor, iría más allá de la mera libertad negativa -que entraña ser libre para decidir sin interferencia ajena. La modesta libertad negativa es, además, perfectamente compatible con la aceptación de que la sociedad, sus normas de comportamiento, y otros aspectos que tienen que ver con nuestra relación con los otros influyen enormemente en la conformación de nuestras preferencias y decisiones (Talyor, 1991). Las demandas externas o el influjo que pueda tener el contexto en nosotros no es algo que se enfrente, como si de un enemigo se tratara, con el yo, sino que el yo presupone esas demandas e influjos (Talyor, 1991). El yo auténtico, por tanto, no se entiende fuera de sus vínculos con los otros. Del mismo modo, no tiene sentido pensar el yo desde un paradigma monológico, sino que sólo lo tiene hacerlo desde un paradigma dialógico.

Estas ideas tienen una traducción política que toma la forma de una propuesta de reivindicación de la diferencia. Taylor advierte que el concep-

3 Es preciso señalar que, como el propio autor afirma, el concepto de «otros significativos» se lo debemos a George Herbert Mead, autor clave para comprender el paradigma dialógico, a cuyos escritos también recurren Honneth y Habermas (Mead, 1934). 
to moderno de igual dignidad puede ocultar el problema de la falta de reconocimiento y, en consecuencia, de sentido de la propia dignidad y valor de los grupos minoritarios. Estos grupos, en su afán de hacerse partícipes de esta dignidad, tratarían de amoldarse a los valores de la cultura hegemónica, renegando de sus particularidades. El «liberalismo de la igual dignidad» (Taylor, 1994: 43), según el autor, parece asumir que hay principios universales, ciegos ante las diferencias. Pero estos principios no son neutrales, sino reflejo de una cultura, que, en las sociedades occidentales, es la dominante. El liberalismo, por tanto, caería en una contradicción al creer en tal neutralidad, puesto que no sería sino otro "particularismo enmascarado de universalidad» (Taylor, 1994: 44).

Axel Honneth es otro de los teóricos del reconocimiento más destacados. Honneth piensa, al igual que Taylor, que el reconocimiento es absolutamente esencial para que podamos sentirnos realizados. No obstante, lo que más preocupa al pensador de la Escuela de Frankfurt es desgranar qué clase de papel juega el reconocimiento en las reivindicaciones de los movimientos sociales.

Honneth, siguiendo a los ya mencionados Hegel y G. H. Mead, así como a Jürgen Habermas y Donald Winnicott, señala que el proceso de individuación, esto es, el proceso por el que una persona adquiere su identidad, no puede ocurrir sino por vía de la socialización.Asimismo, afirma que existen tres esferas de interacción, las cuales estarían conectadas con tres patrones de reconocimiento. Para desarrollar una relación positiva con uno mismo, sería necesario lograr reconocimiento en cada una de estas esferas.

De este modo, si según Hegel existían tres condiciones necesarias para la libertad personal -familia, sociedad civil y estado-, Honneth defenderá que existen tres tipos de reconocimiento que definen la identidad personal, y también tres tipos de actitudes morales -que juntas conformarían lo que él denomina el 'punto de vista moral'-: el amor o cuidado, el respeto moral o reconocimiento jurídico, y la solidaridad. Cada una de estas dimensiones constituiría una forma de integración social: mediante el cuidado y el amor establecemos lazos afectivos con los otros, y nos sentimos reconocidos en esa esfera íntima, puesto que adquirimos conciencia de que nuestras necesidades y anhelos son importantes para otras personas; mediante el reconocimiento moral y jurídico, adquirimos conciencia de que somos merecedores de un trato igual, e igualmente responsables por nuestras acciones; mediante los vínculos de solidaridad somos reconocidos como unos individuos cuyas acciones son valiosas, o están bien valoradas, por una comunidad (Honneth, 1997). 
Para gozar de una identidad íntegra, no patológica, las personas, que tenemos un fuerte sentido de la reciprocidad, necesitamos gozar de reconocimiento, y éste debe verse satisfecho en tres dimensiones vinculadas a las esferas que hemos descrito: autoconfianza, autorespeto y autoestima.

Ahora bien, del mismo modo en que existen formas paradigmáticas de reconocimiento, también existen formas paradigmáticas de menosprecio: el abuso físico y otros tipos de maltrato, la desposesión de derechos y la exclusión social, y la denigración cultural o los agravios relacionados con la vida buena. El modo más elemental de humillación personal se correspondería con las situaciones en las que a una persona se le priva de su disposición sobre el propio cuerpo. Así, "cualquier intento de apoderarse del cuerpo de una persona contra su voluntad, sea cual sea el objetivo buscado provoca [...] humillación» (161). Aunque lo peor, advierte Honneth, no sería ya tanto el dolor físico, como el sentimiento de estar indefenso ante la voluntad de otra persona, y la subsiguiente pérdida de confianza en los demás y en uno mismo.

La segunda forma de humillación tiene que ver con la negación de derechos, entendiendo éstos como aquellas «pretensiones individuales, cuyo cumplimiento social una persona puede legítimamente reclamar, ya que como miembro plenamente valioso de una sociedad participa en su ordenamiento institucional igualitariamente» (162). Esta modalidad de menosprecio lleva aparejada la sensación de no ser reconocido como una persona igualmente poseedora de valor y agencia moral, y constituye un menoscabo al respeto de la persona.

Por último, la desvalorización de los modos de vida individuales o colectivos, que atentan contra la dignidad, el honor o el estatus. Esta forma de humillación «sustrae a los sujetos concernidos toda posibilidad de atribuir un valor social a las propias capacidades» (163), o la imposibilidad de poder referirse a su modo de vivir "como algo a los que, dentro de la comunidad, se le atribuye una significación positiva» (164). Esto conlleva de forma irremisible una pérdida de la autoestima personal.

De acuerdo con Honneth, la negación de reconocimiento es aquello que motiva, y, en cierta medida, también justifica, las luchas sociales. De este modo, los sentimientos de vergüenza y humillación que los sujetos experimentan cuando otros tienen determinadas actitudes hacia ellos les hacen sentir que su reconocimiento social está siendo ilegítimamente negado. Con esto Honneth no quiere decir que allí donde un individuo experimenta vergüenza haya una injusticia, sino simplemente que estas reacciones emocionales nos ponen sobre la pista de una posible injusticia, y que 
éstas, además, constituyen una motivación para que los individuos o grupos de individuos se lancen a luchar por su reconocimiento. Las reivindicaciones de reconocimiento, además, son uno de los motores fundamentales que impulsan el cambio social y el progreso moral de las sociedades.

Multiculturalismo, interculturalismo y políticas del reconocimiento no son lo mismo, desde luego. No obstante, sí que comparten ciertas características, principalmente porque las propuestas multiculturalistas se basan en los presupuestos de la ética y la política del reconocimiento, y porque el interculturalismo, a su vez, es una versión actualizada del multiculturalismo, o que, por lo menos, trata de superar sus deficiencias. Los teóricos del multiculturalismo toman como idea central la necesidad política de reconocer la diferencia, respetarla y buscar formas para darle acomodo. El reconocimiento de la identidad no sólo tendría una dimensión psicológica, sino también política, por cuanto el respeto a la dignidad de la persona forma parte de cualquier esquema de justicia.

No sorprende que la ética y la política del reconocimiento se encuentren estrechamente vinculadas a la emergencia de movimientos sociales relacionados con la lucha por los derechos civiles, el feminismo, y otras formas de lucha por los derechos. Aunque es preciso señalar que no todos los autores extraen las mismas consecuencias normativas de sus teorías. Así, mientras que Honneth desarrolla una teoría meramente descriptiva, pero que retrata con gran agudeza los resortes psicológicos que empujan a las gentes a luchar por ser reconocidos, Taylor no se conforma con subrayar la importancia de los otros en la formación de nuestra identidad y en la necesidad de sentir que nuestra dignidad es respetada. Taylor celebra la diferencia y da el salto del «ser» al «deber ser», abogando por proteger esta diferencia, principalmente otorgando derechos colectivos a las culturas minoritarias, idea que suscitará no pocas críticas, como veremos a continuación.

En una línea de pensamiento similar a la de Taylor, Will Kymlicka defiende que la mera tolerancia de los grupos minoritarios no es suficiente para que sus miembros sean considerados como iguales, sino que la acomodación de estos grupos requiere derechos colectivos o diferenciados (Kymlicka, 1995). Para los teóricos del multiculturalismo el reconocimiento es una cuestión de identidad y respeto, pero también un problema de desventaja política en virtud de un estatus minoritario. Por lo tanto, las reivindicaciones del multiculturalismo no tendrían que ver únicamente con la identidad, sino con cómo la pertenencia a un colectivo minoritario puede conllevar desventajas en el plano social, político e incluso económico. 
Estas reivindicaciones de la diferencia suelen tener dos dimensiones: una individual y una grupal. De este modo, algunos derechos colectivos conciernen al individuo, por ejemplo, si le proporcionan una exención para normas de aplicación general que conllevan violaciones de sus creencias religiosas. Otros, sin embargo, tienen que ver principalmente con la colectividad, como las reivindicaciones de los grupos indígenas o las nacionalidades minoritarias que reclaman un derecho de autodeterminación. En este último caso, se produciría un deslizamiento que no entraña ya el mero reconocimiento de una diferencia valiosa por la comunidad política, sino la ruptura con la comunidad política con la finalidad de formar otra nueva.

\section{ALGUNOS PROBLEMAS DEL MULTICULTURALISMO Y LAS SOLUCIONES DEL INTERCULTURALISMO}

En el apartado anterior hemos visto que el reconocimiento es una dimensión fundamental de la justicia.Ahora bien, la satisfacción de las reivindicaciones planteadas por el multiculturalismo no siempre tiene un desenlace positivo, sino que dicha satisfacción puede desembocar en situaciones injustas para los individuos y en una ausencia de cohesión social que conlleve problemas de convivencia. A continuación, pasamos a enumerar tres de las críticas más frecuentes que ha recibido el multiculturalismo, y algunas de las propuestas del interculturalismo para superar estas dificultades.

\subsection{Minorías dentro de minorías}

Pese a que el multiculturalismo hace referencia a un amplio espectro de reivindicaciones políticas llevadas a cabo por una gran variedad de grupos desaventajados, se ha acusado a esta corriente de pensamiento de prestar demasiada atención a las exigencias de algunos grupos, pero muy poca a otras igualmente legítimas. Así, el multiculturalismo se ha centrado con frecuencia en los inmigrantes, las minorías religiosas, y las minorías étnicas o lingüísticas. Las demandas planteadas por los gays, los discapacitados o las mujeres sólo habrían sido atendidas en un estadio ulterior, crítico con los planteamientos reduccionistas. Charles Taylor, por ejemplo, ha sido enormemente beligerante con las cuestiones relativas a los derechos colectivos del Quebec, pero no ha defendido con el mismo denuedo los asuntos que afectan a los discapacitados o a las mujeres. Esto conlleva problemas 
de diversa índole que pasamos a analizar con más detalle a continuación. Estos problemas derivarían del hecho que las políticas llevadas a cabo para garantizar los derechos de minorías religiosas, culturales o étnicas podrían favorecer a unos miembros del grupo, pero resultar perjudiciales para otros.

Una de las críticas más conocidas en este sentido es la de S. Okin, quien sostiene que el respeto por la diversidad cultural no debe entrañar en modo alguno prácticas discriminatorias hacia las mujeres, o algún tipo de presión para que éstas dejen de reivindicar el reconocimiento de sus derechos (Okin, 1999). La autora explica cómo en los años 80 era habitual que los inmigrantes que llegaban a Francia practicaran la poligamia, cosa que ha propiciado que este tipo de familias sigan existiendo -o por lo menos lo siguieran haciendo en 1999, cuando la autora escribió el ensayo. Okin desaprueba, asimismo, las opiniones que en aquel momento sostuvo la izquierda, cuyas «demandas por la flexibilidad y el respeto por la diversidad, acusando a los oponentes de racismo o de imperialismo cultural» (Okin, 1999: 9), a propósito del velo en las escuelas, no evitaron que no se prestara atención al problema de la poligamia, mucho más grave y dañino para numerosas mujeres y niños. Es decir, que la izquierda, pidiendo ser tolerante con los intolerantes, no acometió un problema de justicia básico. Al parecer, pasaron años hasta que se supo que estas familias convivían hacinadas en pequeños apartamentos, sin privacidad alguna, $y$, a menudo, con problemas de hostilidades, resentimientos o incluso violencia entre las diferentes esposas y los hijos de éstas.

Otros problemas todavía más graves, como la práctica de la ablación, también podrían englobarse en el tipo de actividades que pueden resultar beneficiosas para unos miembros del grupo -en principio, los hombres, que ejercerían de este modo una forma de control sobre las mujeres-, pero perjudiciales para otros. No obstante, es preciso señalar que es poco probable que este tipo de acusaciones puedan lanzarse contra el multiculturalismo en la actualidad, ya que los países de acogida, por lo menos en el caso de Europa, están haciendo los mayores esfuerzos por erradicar estas prácticas. Es decir, que no están abrazando las diferencias culturales sin más, sino que, por lo menos en este tipo de casos, están haciendo un juicio de valor acerca de las prácticas que merece la pena cultivar, y de las que es preciso eliminar. A este respecto, hay una crítica que también es moneda corriente entre los críticos del multiculturalismo: las culturas no pueden intentar preservarse como si de especies en peligro de extinción se tratara -retomaremos esta crítica más adelante. Si acaso, habrá que ver qué rasgos 
son verdaderamente importantes para los individuos que las componen, y ver si son compatibles con los derechos fundamentales. En el caso de la ablación, está claro que, ni estamos hablando de una práctica compatible con la protección de dichos derechos, ni es una práctica tolerada en los estados democráticos liberales, por más que se trate de una costumbre arraigada en algunas culturas.

Otros casos de minorías internas vulnerables, no obstante, no se presentan con la misma claridad que los ejemplos que hemos mencionado, y generan algunas paradojas. Por ejemplo, en Quebec ya han surgido minorías anglófonas dentro de la minoría francófona, la cuales afirman que, si Canadá puede dividirse en función de la lengua, también puede hacerlo Quebec (Elósegui, 1997). En España, se da una paradoja similar con la inmersión lingüística en catalán en el sistema educativo. En principio, los niños deberían poder recibir educación tanto en catalán como en castellano, pero, en la práctica, la lengua vehicular de la enseñanza es el catalán. Esto ha suscitado numerosas críticas. Entre otras razones, porque los niños cuya lengua materna es el castellano se ven impedidos para recibir una educación en dicha lengua, y porque, además, tampoco se garantiza un igual aprendizaje en las dos lenguas oficiales, dada la absoluta prevalencia de una de ellas. ${ }^{4}$ De este modo, de forma similar a lo que ocurre en el Quebec, una lengua minoritaria - el catalán- acaba conformando a otras minorías - las de los bilingües y los castellanohablantes- que terminan siendo perjudicadas por las medidas puestas en marcha -inmersión lingüística- por la que inicialmente era una minoría.

En una línea similar a las reivindicaciones del feminismo, encontramos las de gays y otras minorías que han sufrido discriminación por razones de orientación sexual. Pese a que este tipo de discriminación no se encuentra sólo en las minorías culturales, sino que, con frecuencia, impregna gran parte del tejido social, las minorías cuyas fuertes creencias religiosas rigen aspectos de la vida cotidiana suelen marginar con mayor dureza a estos individuos. Así, estos miembros minoritarios pueden sufrir acoso, agresiones físicas y psicológicas, dificultades para ejercer su libertad sexual u obstáculos para acceder a la participación política.

4 En este punto resulta de interés traer a colación la reciente sentencia 184/2015 de Tribunal Superior de Justicia de Cataluña, que reconoce el derecho de un padre a que su hijo reciba, juntamente con sus compañeros de clase, una enseñanza que incluya el castellano como lengua vehicular en una proporción razonable. 


\subsection{Esencialismo}

Esta crítica iría encaminada a disentir de la opinión según la cual las culturas serían una suerte de entidades homogéneas, congeladas en el tiempo, perennes e inmutables. Las culturas no son impermeables al cambio. A lo largo del tiempo, se da lo que J. Peña denomina una «hibridación cultural» constante, que hace que las sociedades y las culturas se influyan las unas a las otras continuamente (2010: 200). Los usos y las costumbres, por tanto, son algo cambiante y dinámico, en perpetuo intercambio con otros usos y costumbres.

Según S. Benhabib creer que existe algo así como «una pureza de las culturas» es falaz, y también lo es tratar de «identificarlas como totalidades significativas diferenciadas». De acuerdo con la autora, «las culturas son prácticas humanas complejas de significación y representación, de organización y atribución, divididas internamente por relatos en conflicto. Las culturas se crean a partir de diálogos complejos con otras culturas» (Benhabib, 2006: 10).

De este modo, no sólo resulta enormemente difícil delimitar a qué nos referimos cuando hablamos de la cultura ' $x$ ', sino que, además, no podemos esperar que una persona se comporte de un modo determinado por su mera pertenencia a una etnia, su procedencia geográfica o sus orígenes familiares. Si el esencialismo difícilmente puede predicarse de una cultura, aún menos puede predicarse de las personas que tienen algún vínculo con ella.

La crítica a la que hemos aludido en el punto anterior vuelve a ser válida aquí: las culturas no pueden equipararse a especies naturales que deben tratar de preservarse. En primer lugar, porque la tendencia natural de las culturas las dirige hacia la hibridación constante y, en segundo lugar, porque, si para conservar una cultura es preciso atropellar los derechos de los individuos que la conforman, entonces no tiene sentido preservarla, o, para expresarlo con mayor precisión, no tiene sentido hacerlo en un estadio que no sea compatible con las libertades individuales.

\subsection{Aislamiento y ausencia de cohesión social}

Otra de las objeciones más frecuentes al multiculturalismo es que fomenta que la gente de diferentes culturas y religiones se encierren en sus propias prácticas. Esto conllevaría que las personas pertenecientes a las minorías no se relacionaran con otros que no formaran parte de su propio 
grupo. Tampoco se insistiría, por tanto, en que se integraran o que establecieran intercambios o lazos de algún tipo fuera con las personas externas al grupo. Del mismo modo, el recurso al multiculturalismo animaría a las minorías a concentrarse en aquellas cosas que les diferencian de los demás, antes que a tener presentes aquellas que les unen, aumentando todavía más las tensiones inherentes a la convivencia en diversidad (Vertovec y Wessendorf, 2010).

En este punto también es preciso preguntarse si la asimilación debe tener siempre una connotación negativa. Y la respuesta más prudente parece ser que no siempre. Como hemos visto en el primer punto hay usos y costumbres, como la poligamia o la ablación, por mencionar dos casos extremos, que son incompatibles con la integridad física y psicológica, y, por lo tanto, el respeto por la dignidad de las personas. En consecuencia, resulta necesario demandar un amoldamiento en algunos aspectos irrenunciables, como el respeto por los derechos humanos o por el estado de derecho, tal y como defenderemos en el último apartado del presente trabajo.

Otras prácticas no serían tan extremas, aunque, sin ser enjuiciables desde un punto de vista penal, sí que entrañarían dificultades para la convivencia y la cohesión social.T. Kuran ha estudiado cómo un conjunto de actividades, que normalmente no tienen significado étnico alguno, pueden llegar a convertirse en auténticos rituales de identidad. Esto es lo que el autor denomina fenómenos de etnización. En estos procesos, actividades cotidianas como comer, leer o el ocio pasan a estar modulados por patrones preestablecidos -y definidos en función de la pertenencia a una etnia. Kuran advierte que estos cambios se suelen traducir en una participación en política también guiada por la idea de etnia. El resultado es una transformación de las normas sociales, los códigos de comportamiento, y, en consecuencia, de las conductas y actitudes de los individuos que desean lograr la aceptación social. Así, el comportamiento de los individuos no pasaría ya por algún tipo de integración o convivencia armónica con otras identidades, sino por la exacerbación de los rasgos diferenciales para lograr mayor aceptación dentro del grupo minoritario, encerrándolo de este modo dentro de un rasgo de su identidad, que totaliza a todos los demás (Kuran, 1998).

\subsection{Las ventajas del interculturalismo}

Pese a que la noción de «interculturalismo» no es nueva, hasta hace relativamente poco tiempo no ha adquirido pujanza en la literatura académi- 
ca, y esto ha sido debido, en parte, a la utilización del término por autores como Bouchard (2011), Gagnon y Iacovino (2007) que lo han empleado para hablar de la experiencia canadiense. En España, autores como Elósegui (1997), Cortina (2009) o Conill (2002) llevan algunos años hablando de interculturalismo. Por último, hay quien señala que la idea de diálogo intercultural lleva presente también algún tiempo en las políticas públicas llevadas a cabo por algunos gobiernos, como, por ejemplo, programas educativos en Alemania y Grecia, comisiones belgas sobre diversidad cultural, o la celebración en 2008 del Año Europeo del Diálogo Intercultural (Meer y Modood, 2012).

A grandes rasgos, las diversas concepciones del interculturalismo resumen las ventajas de su propuesta en cuatro aspectos básicos: 1) el interculturalismo está basado en el diálogo, mientras que el multiculturalismo no suele ir más allá de la defensa de una mera coexistencia; 2) el interculturalismo tiene una menor tendencia a encerrar a los diferentes grupos en sí mismos; 3) desde el interculturalismo es más sencillo comprometerse con una idea de unidad, o de pertenencia a una comunidad más amplia, encaminada a fomentar la cohesión social; 4) mientras que el multiculturalismo puede ser permisivo con prácticas iliberales, el interculturalismo proporciona mejores herramientas para que los miembros de una cultura la examinen de forma crítica, puesto que el diálogo intercultural les permite romper el solipsismo grupal. ${ }^{5}$

No obstante, como hemos señalado al principio del texto, no todos los autores consideran que el interculturalismo sea capaz realmente de ir más allá del multiculturalismo. Taylor incluso afirma que en Europa existe una suerte de «retórica anti-multiculturalista», porque los europeos asumimos que «demasiado énfasis en el reconocimiento de las diferencias culturales favorecerá un apartamiento en guetos, y un rechazo a la hora de aceptar la ética política de la de la democracia liberal misma» (Taylor, 2012: 2). A lo que el autor añade que la culpa de este tipo de fenómenos no es del multiculturalismo, sino de los fallos de la sociedad de acogida, al no promover políticas de integración y erradicación de la discriminación. En cualquier caso, la separación conceptual de una y otra propuesta permiten poner sobre la mesa algunos de los problemas de la convivencia en las sociedades contemporáneas, por lo que, aunque sólo sea como mera guía para ubicar estas cuestiones, es una distinción que resulta útil.

5 Esta lista es una elaboración propia a partir de Meer y Modood (2012: 177). 
M. Elósegui también considera que, frente al asimilacionismo, que entraña que una cultura se imponga sobre las otras, y el multiculturalismo, que conlleva el peligro de la ignorancia recíproca, el interculturalismo tiene la virtud de plantear una convivencia en la diversidad. El interculturalismo entrañaría una actitud de apertura hacia el otro, o, en otras palabras, una «Voluntad de traspasar la propia particularidad» (Elósegui, 1997: 25). En este sentido, el interculturalismo superaría el peligro de esencialismo al que nos hemos referido, puesto que lo que se fomentaría es exponer la propia cultura al intercambio.

Por otra parte, también se avanzaría hacia la cohesión social, puesto que, de acuerdo con la autora, el interculturalismo defiende que «detrás de la diversidad hay unos valores comunes», y que esto, además, «hace posible compartir una legislación que consagre la universalidad de los derechos y el pluralismo cultural» (25). Esto es, que desde cualesquiera doctrinas comprehensivas del bien, los ciudadanos podrían estar de acuerdo en unos mínimos de justicia plasmados en la ley, ley que a su vez protegería la pluralidad social siempre que ésta fuera respetuosa con los derechos individuales.

En La lucha por el reconocimiento en el estado democrático de derecho, Habermas (1999) da cuenta de la siguiente paradoja: las luchas por el reconocimiento son colectivas, puesto que son llevadas a cabo por actores colectivos; asimismo, estas luchas persiguen fines que también son colectivos, y, por último, los actores pelean por bienes que son colectivos. No obstante, el discurso jurídico habla de derechos del individuo, porque considera que éste es realmente el auténtico titular de los mismos. ${ }^{6}$

Dada esta paradoja -actores, reivindicaciones, y bienes colectivos, pero protegidos por un sistema en el que la titularidad de los derechos es individual-, Habermas se pregunta cómo conciliar la teoría de los derechos y las reivindicaciones que tienen que ver con la identidad colectiva. El autor, al igual que otros pensadores a los que nos hemos referido con anterioridad, como Taylor o Honneth, considera que la identidad tiene una dimensión intersubjetiva. Las culturas y tradiciones conforman un mundo de la vida que porporciona a las personas unas experiencias compartidas $y$, en consecuencia, una autocomprensión también compartida. Ahora bien, la salvaguardia de las tradiciones y de las formas de vida que dan forma a las

6 Hay quien, en contra de la opinión de Habermas, considera que existen los derechos colectivos, de tal modo que éstos no sólo se ejercerían colectivamente, sino que sus titulares serían también entes colectivos. Esta idea se ha ligado en los últimos años a los pueblos indígenas de América Latina y ha pasado a ser moneda corriente en el vocabulario de las Naciones Unidas. Ver: http://unric.org/en/ indigenous-people/27309-individual-vs-collective-rights 
identidades debe, en último término, estar al servicio del reconocimiento de las personas. Es decir, que lo que las reivindicaciones colectivas tienen por meta no es otra cosa que proporcionar un reconocimiento a los individuos que componen la colectividad. Habermas añade que esta forma de atención «no tiene de ningún modo el sentido de una protección administrativa de las especies» (Habermas, 1999: 210). Así pues, no tiene sentido tratar de preservar las formas de vida culturales como si de especies en peligro de extinción se tratara, puesto que éstas se reproducen porque hay gente dispuesta a abrazarlas y "grabarlas en sus estructuras de personalidad» (210). Las culturas no son formas de vida estáticas, sino que son los individuos los que se adhieren a ellas y, en su proceso de apropiación las van transformando.

Otro aspecto a tener en cuenta es que, de acuerdo con sus defensores, el interculturalismo proporciona una ventaja clara respecto al multiculturalismo, en el hecho de concebir a los individuos haciendo hincapié en su capacidad de estar abiertos a interactuar con otras tradiciones y culturas, y, en consecuencia, a ser críticos con su herencia. La identificación de los individuos con una comunidad es compleja y se articula de diversas formas. Es lógico que una persona pueda desear tomar distancia respecto a sus propias adhesiones y ser crítica con ellas, o que pueda desear escoger diferentes grados de compromiso con una identidad determinada. Por ejemplo, una mujer puede ser musulmana, pero rechazar la poligamia o el uso del velo. Por otra parte, una persona puede sentir un vínculo de unión con otras personas con las que comparte raza o comunidad política, pero este vínculo jamás debería ser instrumentalizado por terceros en su propio beneficio (Cortina, 2009).

Por último, T. Cantle (2012) defiende las ventajas de la propuesta interculturalista del siguiente modo:

\footnotetext{
El concepto de interculturalismo tiene que ver con la creación de una cultura de la apertura que desafíe efectivamente la política de la identidad y el afianzamiento de la separación de comunidades basadas en una noción de otredad.Al mismo tiempo, es un proceso dinámico en el que habrá algunas tensiones y conflictos como parte necesaria de un cambio social en el que [...] la diversidad y la globalización sean reconocidas como características permanentes de la sociedad que deben ser abrazadas, más que temidas (143).
}

Cantle, en consecuencia, también considera que el interculturalismo contiene un conjunto de virtudes de las que carece el multiculturalismo. Frente a la cerrazón de las políticas de la identidad, que acentuarían las diferencias y, con ello, el desarrollo de actitudes negativas y prejuicios, la perspectiva del interculturalismo buscaría tender puentes entre individuos 
y grupos. La interacción entre diferentes serviría para derribar estereotipos, promover una tolerancia más allá de la mera coexistencia, y reforzar los lazos de confianza y cohesión social. Esta interacción serviría, asimismo, para solucionar conflictos o tensiones que pueden surgir entre las reivindicaciones relacionadas con las identidades culturales y las reivindicaciones individuales de otro tipo -por ejemplo, de las mujeres. En último lugar, el interculturalismo tendría una especial preocupación por el presente y el futuro, más que por los hechos acontecidos en el pasado, los cuales, pese a tener una importancia indudable en la conformación de las culturas, no pueden prevalecer sobre los hechos y necesidades del presente y el futuro. Es decir, que no podemos incurrir en injusticias en el presente para tratar de resarcir injusticias pasadas.

\section{EL PATRIOTISMO CONSTITUCIONAL COMO FÓRMULA DE COHESIÓN SOCIAL Y EL PAPEL DE LA SOCIEDAD CIVIL EN LA CONFORMACIÓN DEL DERECHO}

Como se ha señalado al principio del presente artículo, si bien el reconocimiento, y, con él, el respeto por la diversidad son elementos esenciales de toda sociedad que se pretenda justa, nos encontramos con que también es preciso encontrar una fórmula para conciliar esta pluralidad con la cohesión social. En mi opinión, la noción de patriotismo constitucional es una buena opción para lograr articular la diversidad con la unidad, ya que prescinde de toda referencia a ideas étnicas, religiosas o culturales y lo que demanda de los ciudadanos es una razonable adhesión a unos «principios e instituciones que instauran las condiciones de convivencia entre las diferentes formas de vida» (Velasco, 2002: 35). A mi juicio, la dimensión del reconocimiento se puede complementar con esta otra propuesta, para lograr la necesaria unidad y cohesión que requiere toda sociedad. ${ }^{7}$

La expresión patriotismo constitucional fue acuñada por el jurista y politólogo Dolf Sternberger, si bien debemos a Jürgen Habermas su posterior difusión, cuya propuesta se sitúa en el contexto del debate académico denominado «disputa de los historiadores», en el que se planteó en qué medida los alemanes podían sentirse orgullosos de su propia tradición

7 Jean Werner Müller (2012) ha sostenido que, pese a que este no era el propósito inicial de Sternberger y Habermas en los 70 y en los 80, hoy en día la noción de patriotismo constitucional resulta particularmente relevante para lidiar con los desafios derivados de la diversidad interna en los estados-nación -que ha aumentado en los últimos años debido a las migraciones-, y con miras a fomentar lealtades supranacionales, como ocurre con la Unión Europea. 
nacional, dado que ésta había dado lugar al holocausto. La discusión versaba, asimismo, sobre la forma en que los alemanes podían reconciliarse con su historia reciente. Habermas reivindicó la idea de patriotismo constitucional como posible solución al dilema.

Lo que el patriotismo constitucional requiere de los ciudadanos es una modesta adhesión a la ley y al sistema político que posibilitan la libertad civil, a diferencia de otras formas de patriotismo que demandan compartir otros aspectos como la etnia, la cultura, o las creencias morales. Así pues, existiría una nítida distinción «entre una concepción cívica y una concepción étnico-cultural de la identidad colectiva» (Velasco, 2002: 34).

Según Habermas, el derecho es neutral, por lo menos en cierto sentido, y por ello permite que todos los ciudadanos puedan compartir un respeto y adhesión por él (Habermas, 1999). En las complejas sociedades actuales es difícil que haya un consenso sobre los valores últimos. Aun así, lo que sí que puede haber es un consenso acerca de lo que entendemos por un procedimiento legislativo legítimo y por un ejercicio del poder legítimo. Lo que existe, por tanto, es un universalismo de los principios jurídicos, que se refleja en la cultura política de los ciudadanos de un estado democrático. Tanto el sistema de derechos como los principios de estado de derecho tienen, por tanto, cierto grado de universalidad y, por ello, se pueden suscribir desde cualquier cultura. Lo que propugna el patriotismo constitucional, por tanto, es concebir la identidad común de una comunidad política como identidad cívica.

De acuerdo con Habermas, además, esta cuestión es de particular relevancia para pensar acerca de la inmigración y las sociedades multiculturales. Las migraciones hacen que la sociedad cambie su fisonomía no sólo en un sentido físico, sino también ético-cultural. Dado que los inmigrantes no pueden ser obligados a renunciar a sus formas de vida y concepciones del mundo particulares, la presencia de estas tradiciones hace que el horizonte desde el que el conjunto de la ciudadanía interpreta los principios constitucionales vaya cambiando. La ciudadanía, insistimos, se renueva constantemente en dos sentidos: uno físico, porque las migraciones y la llegada de nuevas generaciones hacen que el demos vaya cambiando; y otro éticocultural, porque la comunidad política pasa a autocomprenderse de un modo distinto, dada la reinterpretación de los principios constitucionales, hecho que, a su vez propicia que el derecho vaya cambiando con arreglo a estas interpretaciones. Así pues, la sociedad civil tiene un papel fundamental como impulsora de los cambios sociales haciendo que sus reivindicaciones se plasmen en el derecho. Eso sí, los límites que nunca podría llegar 
a traspasar en su impulso transformador son los que impone el estado de derecho y el respeto por los derechos fundamentales. Un patriotismo de la Constitución siempre tiene claro estos límites, puesto que entiendo que el respeto por el estado de derecho y los derechos fundamentales son precisamente lo que propicia unas condiciones adecuadas de convivencia y disfrute de las libertades.

Así pues, la principal virtud del patriotismo constitucional es su capacidad integradora, puesto que los sujetos pueden mantener sus identificaciones con formas de vida particulares, pero, al mismo tiempo, compartir una identidad cívica común.

\section{CONCLUSIONES}

Como hemos visto, pese a que no hay consenso respecto a si el interculturalismo aporta alguna novedad al multiculturalismo, o si este último ya contiene todas las soluciones que viene a proponer el primero, parece claro que lo que los defensores del interculturalismo aseguran es que, mientras que el multiculturalismo tiende a la preservación de la herencia cultural, su propuesta se caracteriza por la apertura al cambio y a la circulación de ideas, costumbres y perspectivas.

Por otra parte, mientras que los partidarios del multiculturalismo suelen reclamar la necesidad de proteger la diferencia y los derechos colectivos, el interculturalismo parece ser más proclive a insistir en la centralidad del individuo, superando así no sólo las injusticias en las que incurre el multiculturalismo, sino también los obstáculos para la convivencia y la cohesión social que pueden conllevar.

A lo largo del trabajo hemos hecho notar que la forja de la identidad y la personalidad no pueden entenderse si no es en relación a nuestro entorno, a la herencia recibida y a la interacción con los otros significativos. Ahora bien, la identidad individual puede realizarse en múltiples planos, y es a cada individuo a quien compete decidir cuál es la importancia que tienen sus adscripciones. No es tarea, por tanto, de otros decidir a qué cultura pertenece una persona, sino que sólo ella misma debe decidir qué aspectos de aquello que le ha sido transmitido merecen ser cultivados o tienen un lugar privilegiado en sus afectos, y cuáles deben ser puestos a revisión o quedar en un plano secundario. Cualquier pretensión de concebir el reconocimiento como una dimensión esencial de la justicia social 
debe tener en cuenta que esta forma de justicia también entraña respetar la capacidad de elección del individuo.

Del mismo modo, un individuo no puede ser identificado en base a estereotipos, puesto que es a él a quien le corresponde determinar si quiere ser reconocido de una forma u otra. Hay identidades que no siempre son prioritarias, o no son las únicas que cuentan. Una persona puede pertenecer a una minoría, pero preferir que los otros vean en él a un buen profesional, una persona compasiva, o a un ser humano dotado de ingenio $u$ otras habilidades, por más que el hecho de pertenecer a ese grupo sea también una parte de su identidad. No hay que olvidar que, en numerosas ocasiones, como ya hemos visto, una pretendida visión compartida del mundo finalmente resulta ser fruto de relaciones de poder antes que de auténticas elecciones personales. Las identidades deben ser pensadas no como algo singular, sino como algo múltiple y rico. Desenmascarar este tipo de dinámicas perversas también es un elemento esencial de la justicia social.

Desde aquí hemos propuesto la idea de patriotismo constitucional como mecanismo para articular la identidad cívica y articular la diversidad con la cohesión social. El papel que cumple aquí la sociedad civil, como hemos visto, es fundamental: por una parte, porque participa en el proceso de conformación del derecho, y de esta forma va reinterpretando los principios constitucionales a la luz de los nuevo tiempos, $y$, por otra, porque en sus manos está rechazar una identidad compartida con sus conciudadanos basada principalmente en rasgos étnicos, religiosos o vinculados a una forma cultural particular, y escoger una identidad fundada en la común adhesión a los principios que protegen la seguridad y la capacidad de elección de todos.

\section{BIBLIOGRAFÍA}

BENHABIB, S. (2006): Las reivindicaciones de la cultura. Igualdad y diversidad en la era global, Buenos Aires, Katz.

Bouchard, G. (2011): «What is interculturalism?», McGill Law Journal, 56, 2, pp. $435-468$.

CANTLE, T. (2012): Interculturalism. The new era of cobesion and diversity, Londres, Palgrave Macmillan, 2012.

Conill, J. (2002): Glosario para una sociedad intercultural, Valencia, Bancaja. 
Cortina, A. (2009): Ciudadanos del mundo. Hacia una teoría de la ciudadanía, Madrid, Alianza.

Elósegui, M. (1997): "Asimilacionismo, multiculturalismo e interculturalismo», Claves de Razón Práctica, 74, pp. 24-32.

Fraser, N. (1996): «Social Justice in the age of identity politics, redistribution, recognition and participation», Tanner Lecture on Human Values.

Gagnon, A.G., y IACOvino, R. (2007): Federalism, citizenship and Quebec, debating multinationalism, Toronto, University of Toronto Chicago Press.

Gutmann,A. (2003): Identity in Democracy, Princeton, Princeton University Press.

Habermas, J. (1999): La inclusión del otro. Estudios de teoría política, Barcelona, Paidós.

Honneth, A. (1997): La lucha por el reconocimiento, por una gramática moral de los conflictos sociales, Barcelona, Crítica.

- (1998): «Recognition» en Routledge Encyclopedia of Philosophy, accesado 22 de octubre de 2015.

Kuran, T. (1998): "Ethnic Norms and Their Transformation through Reputational Cascades», The Journal of Legal Studies, 27, 2, pp. 623659.

Kymlicka, W. (1995): Multicultural Citizenship, A Liberal Theory of Minority Rights, Oxford, Oxford University Press.

- (2010): «The rise and fall of multiculturalism? New debates on inclusion and accommodation in diverse societies», International Social Science Journal, 199, 61, pp. 97-112.

Mead, G. H. (1934): Mind, Self, and Society, Chicago, University of Chicago Press,.

MeER, N., Y TARIQ, M. (2012): «How does Interculturalism Contrast withMulticulturalism?», Journal of Intercultural Studies, 33, 2, pp. 175-196.

OKIN, S. (1999): «Is Multiculturalism Bad for Women?» en CoHEN, J. y otros (eds.) (1999): Is Multiculturalism Bad for Women?, Princeton, Princeton University Press.

Muller, J. V. (2012): «Constitutional Patriotism Beyond the Nation State, Human Rights, Constitutional Necessity and the Limits of Pluralism», Cardozo Law Review, 33, 5, pp. 1923-1935.

PEÑA, J. (2010): La ciudad sin murallas. Política en clave cosmopolita, Madrid, El viejo topo. 
Rosales, J.M. (2001): "Estudio preliminar», en Sternberger, D. (2001) Patriotismo constitucional, Bogotá, Universidad Externado de Colombia.

Rosales, J. M. (1997): Patriotismo, nacionalismo y ciudadanía, en defensa de un cosmopolitismo cívico, Bogotá, Universidad Externado de Colombia.

Sternberger, D. (2001): Patriotismo constitucional, Bogotá, Universidad Externado de Colombia.

Talyor, Ch. (1991): The Ethics of Autbenticity, Cambridge, Harvard University Press.

- (1994): "The Politics of Recognition» en Gutmann, A. (ed.) (1991): Multiculturalism, examining the politics of recognition, Princeton University Press.

- (2012): «Interculturalism or multiculturalism?», Philosophy \& Social Criticism 38, 4-5, pp. 413-423.

Torrens, X. (2006): «Multiculturalismo», en Mellón A. (ed.) (2006): Ideologías $y$ movimientos políticos contemporáneos, pp. 381-404. Madrid, Tecnos.

Velasco, J.C. (2002): «Patriotismo constitucional y republicanismo», Claves de Razón Práctica, 125, pp. 33-40.

Vertovec, S. Y Susanne W. (2010): «Introduction, assessing the backlash against multiculturalism» en VerTovec, S. y SusAnne W. (eds.) (2010): The multiculturalism backlash, European discourses, policies, and practices, NY, Routledge.

Wieviorka, M. (2012): «Multiculturalism, a Concept to be Redefined and Certainly Not Replaced by the Extremely Vague Term of Interculturalism», Journal of Intercultural Studies 33, 2, pp. 225-231.

Young, I.M. (1990): Justice and the Politics of Difference, Princeton, Princeton University Press. 